\title{
INTRAUTERINE FETAL DEATHS; FREQUENCY OF CAUSES AT A TERTIARY CARE HOSPITAL
}

1. MBBS, FCPS

Consultant Gynecologist

Social security hospital, Sialkot

2. Assistant Professor,

Obstetrics and Gynecology

Islam Medical College, Sialkot

3. Senior registrar

CMH Lahore Medical College

Lahore.

4. $3^{\text {rd }}$ year MBBS

CMH Lahore Medical College Lahore.

\section{Correspondence Address:}

Dr Uzma Asif

House No: 24-B, Askari - 2 B,

Sialkot Cantt

druzma830@yahoo.co.uk

Article received on: 29/01/2016

Accepted for publication:

15/04/2016

Received after proof reading:

$26 / 05 / 2016$

\section{Dr. Nosheen Bano', Dr Uzma Asif ${ }^{2}$, Dr. Saima Qamar ${ }^{3}$, Midhat Asif ${ }^{4}$}

ABSTRACT... Objectives: The objective of the study was to identify the frequency of causes of intrauterine fetal deaths in patients presenting to a tertiary care setting. Study Design: Cross Sectional Survey. Settings: Study was conducted at department of obstetrics and gynaecology, unit- ii Lahore General Hospital, postgraduate medical institute, Lahore. Duration: From April 2010 to October 2010. Results: Majority of the patients of the subjects under the study were recorded between 21-30 years of age with mean age 26.24 \pm 3.58 years. Distribution of of causes of intrauterine fetal death shows $42 \%(n=63)$ with no cause, $23.33 \%(n=35)$ with more than two causes, $20.67 \%(n=31)$ with two causes and $14 \%(n=21)$ with one cause. Hypertensive disorders $41.43 \%(n=62)$, unexplained $42 \%(n=63), 35.33 \%(n=53)$ were found with physical injuries, $17 \%(n=24)$ with congenital anomaly, antiphospholipid syndrome in $14 \%(n=21)$ while diabetes mellitus was found in $12.67 \%(n=19)$ cases. Most of the women were found primiparity i.e. $49.33 \%(n=74)$, Multi para $2-4$ in $31.33 \%(n=47)$ and only $19.34 \%(n=29)$ were found with $>$ 4 grand multi para. Conclusion: The frequency of causes of intrauterine fetal death in patients presenting to a tertiary care setting shows most of the patients with hypertensive disorders, unexplained and physical injuries while antiphospholipid syndrome and diabetes mellitus were found the less common causes.

Key Words: Intrauterine fetal death, frequency of causes, hypertensive disorders, unexplained, physical injuries.

Article Citation: Bano N, Asif U, Qmar S, Asif M. Intrauterine fetal deaths; frequency of causes at a tertiary care hospital. Professional Med J 2016;23(6):731-735. DOI: 10.17957/TPMJ/16.3235

\section{INTRODUCTION}

Death of fetus during pregnancy is a psychological traumata and the most stressful life event for the parents accompanied by emotional distress and symptoms of depression. ${ }^{1} \mathrm{~A}$ still birth is defined as a child delivering after the $24^{\text {th }}$ completed weeks of pregnancy, which does not show any sign of life at any time after being delivered. Stillbirths include death occurring before the onset of labour as well as during labour (intrapartum death). It complicates about $1 \%$ of pregnancies. In more than $50 \%$ cases, cause of fetal death cannot be determined. Fetal death is the largest subgroup of perinatal mortality worldwide. Worldwide at least 3.2 million still births occurs each year. ${ }^{2}$ The majority of these deaths occur in developing countries. In developed countries approximately 1 in 200 pregnancies ends in stillbirth. In the US approximately 25,000 stillbirths are reported annually. ${ }^{3}$

As far as birth weight and gestational age are concerned, there is no consensus internationally for reporting fetal death and perinatal mortality. WHO revised the $10^{\text {th }}$ of the International Classification of diseases (ICD-10) in 1992. It defines perinatal mortality starting from 22 completed weeks of gestation onwards (birth weight is normally about 500 grams) and ending 7 days postnatally. ${ }^{4}$

There has been no reduction in the intrauterine fetal death rate over the past 20 years. While neonatal death and intrapartum fetal death rates have continued to decline with improvements in care, antepartum fetal death has emerged as the leading category of perinatal mortality. ${ }^{5}$ 
Some Factors causing intra uterine fetal death (IUD) like syphilis, hypertension, toxemia of pregnancy and Rh isommunization, have shown significant decrease over the last few decades. ${ }^{6}$ However, fetal deaths continue to occur due to malformations infections, intrauterine growth retardation, and placental abruption. In the past several decades, perinatal mortality and neonatal death rate has gone down, however fetal deaths have not decreased as expected. ${ }^{7}$

It has become difficult to prevent Fetal deaths because the etiological factors have not been properly identified. Other problems faced are the lack of uniformity in data collection and classification of causes of fetal death. These problems make comparisons and accurate reporting difficult in fetal deaths. Past studies of fetal deaths included fetuses having weight more than 1000 whereas some studies included antepartum and others studied intrapartum fetal deaths. It caused a lot of confusion in data interpretations of risk factors and causes of fetal death. ${ }^{8,9,10}$ In a study done in 2000 in Iran, 1020 cases of fetal deaths were recorded. In this study $49.6 \%$ of which were male fetuses mostly occurring during summer time (37.6\%). ${ }^{11,12}$ Among the cases, $75.69 \%$ of cases were unknown, $17.65 \%$ were due to postpartum delivery and intra uterine growth retardation, complicated delivery (1.76\%), congenital anomalies (1.57\%), complications of placenta and amniotic membrane (1.37\%) and trauma at delivery $(0.78 \%)$. In Asia many studies have revealed that the incidence of IUD (as defined by World Health Organization) has gone up from $0.83 \%$ (1997) to $2.2 \%$ (2001). These results need further research.

The purpose of this study was to determine frequency of causes of Intrauterine Fetal Deaths in Patients at a tertiary care hospital in our set up. It will help us to generate data about common preventable causes and plan strategies to reduce their incidence in local population.

\section{PATIENTS AND METHODS}

This cross sectional study was conducted at department of obstetrics and Gynaecology,
Unit-I, Lahore General Hospital, (Postgraduate Medical Institute), Lahore from $14^{\text {th }}$ April 2010 to $13^{\text {th }}$ October 2010. Sample size of 150 cases was selected through non-probability purposive sampling. Pregnant women ranging from 1545 years of age with any parity presenting with intrauterine fetal death (IUD) after 24 completed weeks of gestation assessed on USG were included in the study. Cases with IUD with multiple gestation, IUD with ruptured uterus, and due to trauma were excluded from the study. Patients were admitted through outpatient or emergency department. Informed consent was taken from all patients. Their demographic profile like name, age, gestational age, parity were recorded. To determine the causes of IUD, history of previous pregnancy losses, systemic illnesses like hypertension, diabetes mellitus, drug intake and any other medical illness were recorded on a predesigned proforma. In high risk cases GTT was done. Patients with history of recurrent pregnancy loss were investigated for presence of toxoplasmosis, rubella, cytomegalovirus and herpes infection. Anticardiolipin antibodies / lupus anticoagulant were also done to confirm antiphospholipid syndrome. In IUD patients, after delivery gross physical examination of fetus was done to assess physical injuries (cord prolapsed, knots, bands, strangulation) and congenital anamolies. The cases in which no definitive cause was found were placed in the category of unexplained.

Data collected was entered and analysed by SPSS version 20. Data was presented as mean \pm SD for numerical variables like age. Causes of intrauterine death i.e. maternal systemic illness like diabetes mellitus and hypertension, antiphospolipid syndrome, physical injuries to fetus, fetal congenital anomalies and unexplained factors were presented as frequency and percentages.

\section{RESULTS}

In this study, a total of 150 patients were recruited after fulfilling the inclusion / exclusion criteria to identify the frequency of cases of intrauterine fetal death in patients presenting to a tertiary care 
setting.

Majority of the patients $51.33 \%$ (77), were between 21 - 30 years of age, $28.67 \%$ (43) were between 31 - 40 years, $10.67 \%$ (16) were between 41 45 years. Only $9.33 \%$ (14) were between $15-20$ years. Mean and standard deviation of age was recorded as $26.24 \pm 3.58$ (Table-I.)

Distribution of frequency of causes of IUD shows $42 \%$ (63) with no cause, 23.33 (35) with more than two causes, $20.67 \%$ (31) with two causes and $14 \%$ (21) with only one cause. (Table-II.)

Table-III. shows the causes of IUD, majority of the patients had unexplained cause $42 \%$ (63), hypertension as single cause was seen $5.33 \%(8)$, Diabetes was seen in $4.66 \%$ (7), diabetes with hypertension was seen in $20.66 \%(31)$, antiphospholipid syndrome was seen in $4 \%(06)$. See table 03 for further details.

We recorded the parity of the patients in Table No. 4, most of the women were found primi-parity i.e. $49.33 \%(n=74), 2-4$ in $31.33 \%(n=47)$ and only $19.34 \%(n=29)$ were found with $>4$ para.

\begin{tabular}{|c|c|c|}
\hline Age (in years) & No. of cases & Percentage \\
\hline $15-20$ & 14 & 9.33 \\
\hline $21-30$ & 77 & 51.33 \\
\hline $31-40$ & 43 & 28.67 \\
\hline $41-45$ & 16 & 10.67 \\
\hline Mean and S.D. & \multicolumn{2}{|c|}{$26.24 \pm 3.58$} \\
\hline Total & $\mathbf{1 5 0}$ & $\mathbf{1 0 0}$ \\
\hline
\end{tabular}

Table-l. Age distribution of the subjects $(n=150)$

\begin{tabular}{|c|c|c|}
\hline Frequency of Causes & No. of Patients & Percentage \\
\hline No Cause & 63 & 42 \\
\hline One Cause & 21 & 14 \\
\hline Two Causes & 31 & 20.67 \\
\hline > Two auses & 35 & 23.33 \\
\hline Total & $\mathbf{1 5 0}$ & $\mathbf{1 0 0}$ \\
\hline Table-II. Distribution of frequency of causes of \\
intrauterine fetal death $(n=150)$
\end{tabular}

Note: Patients have more than one cause of intrauterine fetal death, the detail of frequency of causes is given in the next Table-III.

\begin{tabular}{|c|c|c|}
\hline Causes & No. of Patients & Percentage \\
\hline DM only & 07 & $4.66 \%$ \\
\hline HTN only & 08 & $5.33 \%$ \\
\hline DM + HTN & 31 & $20.66 \%$ \\
\hline DM+HTN +FCA & 35 & $23.33 \%$ \\
\hline APS & 06 & $4.00 \%$ \\
\hline Abruptio placentae & 05 & $3.33 \%$ \\
\hline Unexplained & 58 & $38.66 \%$ \\
\hline
\end{tabular}

Table-III. Causes of intrauterine fetal death $(n=150)$

APS =antiphospholipid syndrome, $\mathrm{DM}=$ diabetes mellitus, HTN=hypertension

$\mathrm{FCA}=$ fetal congenital anomalies

\begin{tabular}{|c|c|c|}
\hline Status & No. of cases & Percentage \\
\hline Primi & 74 & 49.33 \\
\hline Multi Para $(2-4)$ & 47 & 31.33 \\
\hline Grand multipar $(>$ 4) & 29 & 19.34 \\
\hline Total & $\mathbf{1 5 0}$ & $\mathbf{1 0 0}$ \\
\hline \multicolumn{2}{|c|}{ Table-IV. Status of parity $(\mathrm{n}=150)$} \\
\hline
\end{tabular}

\section{DISCUSSION}

Stillbirth is regarded the most unfortunate outcome of pregnancy. Every year worldwide, 3.3 million stillbirths are reported. Among these, 97\% stillbirths occur in developing countries. ${ }^{1,2}$ Under reporting is a common problem in developing countries as registries are not available everywhere. It is most likely that an additional 1 2 million stillbirths are not reported. ${ }^{3}$

In advanced countries, fetal deaths (Ante partum) have significantly decreased. However, in developing countries it still remains a major problem especially in South Asian region. Problem is that we lack precise knowledge of the causes of fetal deaths which mandatory for counseling of the couple, its prevention and desired treatment. Fetal deaths occur as the majority of pregnant mothers are not booked in antenatal clinics and are usually referred from remote rural areas which leads to complications of pregnancy and labor.

In my study, majority (60\%) of women were found between 21 - 30 years of age, which 
shows that IUD may occur with advanced age. Women having IUDs suffer form of some form of chromosomal anomalies and congenital anomalies. This phenomenon is commonly seen in elderly women.

A previous study done by Fretts and colleagues ${ }^{5}$ revealed that as pregnancy in elderly women having age more than 35 years has got 1.5 times more risk of fetal death. Smith has suggested that maternal age is not the only reason for fetal deaths. However diseases like diabetes and hypertension along with advanced age of mothers act as a confounding variable. ${ }^{4}$

In my study, majority of the patients (50.66\%) were multipara, we may say that multiparity is also associated with advanced age group. However, multiparity is not a risk factor of IUD as such.

High blood pressure can increase the risk of IUD, as in our study, we found a significant incidence of high blood pressure. High blood pressure may be due to the advanced age and multi - parity as well, our findings are in agreement with the study conducted in Iran. ${ }^{5}$ That study also shows patients were having a significantly higher blood pressure.

Increased risk of hemorrhage during $3^{\text {rd }}$ trimester may be a cause of IUD. Some of the IUD cases $(5,3.33 \%)$ in our study were accompanied with placental abruption. Surkan in his study has found a strong correlation between the IUD, placental abruption and placenta previa. ${ }^{6}$ Incerpi found that out of 178 cases of IUDs, 27 cases of IUDs were caused by placental abruption. ${ }^{7}$

In our tertiary level hospital, only few gynecologists and midwives are availabe around the clock, to handle a large number of deliveries per year. This shortage of trained staff may be focused and health facilities for care of pregnant ladies may be provided at maximum.

\section{CONCLUSION}

Hypertensive disorders, diabetes mellitus, fetal congenital anomalies were found as the most common causes of IUD in patients presenting to a tertiary care setting. However a significant number of IUDs remained unexplained. In future further research with postmortem facilities and chromosomal studies may unreveal the mystery of intrauterine death.

\section{Copyright(C) 15 Apr, 2016.}

\section{REFERENCES}

1. Murray J, Callan VJ. Predicting adjustment to perinatal death. Br J Med Psychol 1988; 61:237-44.

2. Stanton C, Lawn JE, Rahman H, Wilczynska-Ketende K, Hill K. Stillbirth rates: delivering estimates in $\mathbf{1 9 0}$ countries. Lancet 2006; 367:1487-94.

3. Macdorman MF, Munson ML, Kirmeyer S. Fetal and perinatal mortality, United States, 2004. Natl Vital Stat Rep 2007; 56:1-19.

4. World Health Organization (WHO). International Classification of Diseases, $10^{\text {th }}$ ed. 1992. Geneva.

5. Fretts RC, Boyd ME, Usher RH, Usher HA. The changing pattern of fetal death, 1961-1988. Obstet Gynecol 1992; 79:35-9.

6. Fretts RC. Maternal age and fetal loss. Older women have increased risk of unexplained fetal death. $\mathrm{Br}$ Med J 2001; 322:430.

7. Zhang J, Cal W. Risk factors with antepartum fetal death. Early Hum Dev 1992; 28:193-200.

8. Petitti $D$. The epidemiology of fetal death. Clin Obstet Gynecol 1987; 30:253-8.

9. Fretts $R$, Usher R. causes of fetal death in women of advanced maternal age. Obstetr Gynecol 1997; 89:405.

10. Kochenour N. Other causes of fetal death. Clin Obstet Gynecol 1987; 30:312-9.

11. Rasmussen S. Albrechtsen S, Irgens L, Lorentz M, Dalaker $\mathrm{K}$, Maartmann-Moe et al. Unexplained antepartum fetal death in Norway, 1985-97: diagnostic validation and some epidemiologic aspects. Acta Obstetricia et Gynecologica Scandinavica. 2003; 82(2):109-15.

12. Wen SW, Huizhong K, Sauve MS. Determinants of Intrapartum fetal death in a remote and indigent population in China. J Perinatol 2004; 24(2): 77-8.

13. Goldenberg RL, Thompson C. The infectous origin of still birth. Am J Obstet Gynaecol 2003; 189:861-73. 
14. Lawn JE, Cousens S. Lancet neonatal surviving steering team. 4 million neonatal deaths: When? Where? Why? Lancet 2005; 365:891-900.

15. Lawn JE, Shibuya K, Stein C. No cry at birth: global estimates of intrapartum stillbirth and intrapartumrelated neonatal deaths. Bull World Health Organ 2005; 83:409-17.

16. Smith Get. Life table analysis of the risk of prenatal death at term and post term in singleton pregnancies. Am J Obstet Gynecol 2001;184:489-94
17. Zaidi N, Unexplained Intrauterine Death In the Third Trimester: Poor Predictive Value Of Umbilical Artery Doppler Waveform. The Internet of Gynecol and Obstet 2007; 6:2.

18. Surkan PJ, Dickman SO, Paul W. Cnattinglus, S. Previous preterm and smalifor-gestational-age Births and the subsequent risk of stillbirth. $\mathrm{N}$ Eng $\mathrm{J}$ Med 2004; 350(8):777-85.

19. Incerpi $M H$. Still birth evaluation, what tests are needed? Am J Obstet Gynecol 1998; 178:1121-8.

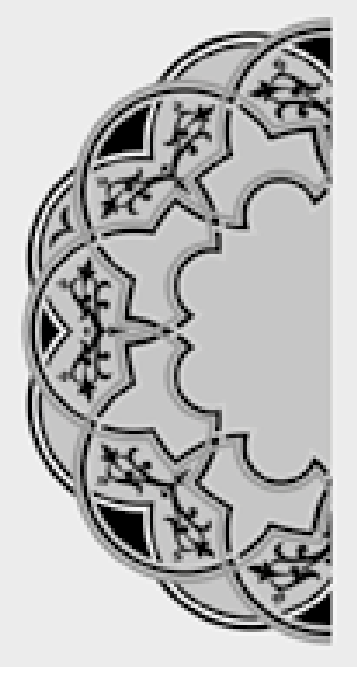

\section{"Great spirits have always faced violent opposition from mediocre minds."}

\section{Einstein}

\section{AUTHORSHIP AND CONTRIBUTION DECLARATION}

\begin{tabular}{|c|l|l|}
\hline Sr. \# & \multicolumn{1}{|c|}{ Author-s Full Name } & \multicolumn{1}{|c|}{ Contribution to the paper } \\
\hline 1 & Dr. Nosheen Bano & $\begin{array}{l}\text { Article Writing \& Data } \\
\text { collection } \\
\text { Article Writing }\end{array}$ \\
2 & Dr Uzma Asif & Article Writing \\
3 & Dr. Saima Qamar & Data collection
\end{tabular}

